\title{
Um simulador virtual para o ensino do Movimento Harmônico Simples desenvolvido utilizando o GeoGebra
}

Antonio Augusto Soares aasoares@ufscar.br

000-0002-2728-124X

作 Sorocaba, São Paulo, Brasil.

\section{Rodrigo do Carmo} prof.rodrigoo@gmail.com Universidade Federal de São Carlos, Sorocaba, São Paulo, Brasil.

\section{RESUMO}

Neste trabalho apresentamos uma proposta de simulador virtual para o ensino do Movimento Harmônico Simples. Desenvolvemos o simulador utilizando o software dinâmico GeoGebra. O simulador obtido apresenta uma interface gráfica bastante leve e objetiva, permitindo ao professor explorar o fenômeno de forma intuitiva junto a seus estudantes do EM. O fato de o código que rege o simulador ser acessível ao usuário permite que o mesmo possa ajustá-lo de acordo com suas necessidades. O simulador apresenta potencial para a melhoria na qualidade do processo ensino-aprendizagem do tema a que se relaciona, podendo levar a um aprendizado com mais significação aos estudantes.
\end{abstract}

PALAVRAS-CHAVE: Ensino de física. Tecnologias da informação e comunicação aplicadas ao ensino. Simulador virtual. GeoGebra. 


\section{INTRODUÇÃO}

Depois de transcorrida mais de uma década e meia do século XXI, é mais que evidente a forte presença das tecnologias da informação e comunicação (TIC) no dia a dia da sociedade. Por exemplo, do aeroporto ao supermercado ou da solicitação de um táxi ao "convívio" social, computadores, tablets e smartphones configuram-se como elementos quase que indispensáveis ao bom funcionamento da vida moderna. Nas escolas de ensino fundamental (EF) e médio (EM), mesmo naquelas onde o caráter sócioeconômico não se apresenta muito favorável, é incontestável a presença desses dispositivos nas mãos dos jovens estudantes além do acesso que os mesmos têm a computadores e à internet. As TIC, então, se configuram como mais um objeto de aprendizagem à disposição de professores e estudantes dos mais variados níveis de ensino.

Cabe, então, aos professores e aos pesquisadores do ensino proceder com o desenvolvimento e análise de propostas e métodos de transposição didática entre os elementos tecnológicos, que são os objetos do saber a ensinar, para um efetivo objeto de ensino. As TIC são ferramentas de apoio para o ensino de ciências, ainda mais quando tratamos da física, principal fomentadora das tecnologias necessárias ao desenvolvimento desses dispositivos. Além disso, por tratar-se de um elemento de uso diário na vida dos estudantes, a implementação de atividades de ensino utilizando as TIC pode apresentar amplo potencial para o desenvolvimento de um ensino repleto de significação para os jovens aprendizes. Como defende Moran (2002), o conhecimento ocorre de forma fundamental no processo de interação e de comunicação entre os elementos envolvidos no processo de ensino. Nesse sentido, dada a atual situação e o acesso praticamente universal às TIC, é mandatório que formas de transpô-las para as salas de aula, principalmente aquelas do EF e EM, sejam propostas, testadas e implementadas.

Diversos trabalhos têm sido realizados no sentido de se desenvolver e/ou propor atividades voltadas ao ensino de física. Alguns deles abordam o uso de sensores embarcados nos dispositivos móveis, outros se valem de simuladores virtuais. Dentre os mais recentes, Vieyra e Vieyra (2014) apresentam uma proposta para análise de forças e do efeito da aceleração da gravidade em parques de diversões utilizando o acelerômetro de um smartphone. Nesse trabalho os autores concluem que tal abordagem leva os estudantes a compreenderem que, por exemplo, na queda livre de uma torre elevada, o peso do indivíduo permanece o mesmo que aquele quando em repouso e que o que realmente muda é o valor da força normal, relacionada ao contato do indivíduo com o assento do brinquedo.

Outra proposta bastante criativa e ao mesmo tempo simples utiliza um smartphone como componente de um pêndulo simples (a massa do pêndulo) onde o próprio dispositivo tecnológico é usado para medir o período de oscilação levando, em seguida, ao cálculo bastante preciso da aceleração da gravidade local (BRIGGLE, 2013). Nesse trabalho, o autor relata que os resultados relacionados à medida do tempo em sua abordagem experimental se afastam apenas da ordem de um centésimo de segundo daquele obtido utilizando dispositivos comerciais para aquisição de dados. Isso mostra o quão precisas podem ser as medidas de intervalos de tempo utilizando um smartphone.

Em relação ao uso dos simuladores virtuais, no que tange à física moderna e 
que tal simulador associado a uma atividade experimental conferiu aos estudantes uma predisposição ao aprendizado do tema que, por sua vez, tornou-se mais significativo. Escobar e colaboradores (2016) apresentam uma proposta de utilização de um laboratório virtual para o estudo dos conceitos relacionados ao eletromagnetismo, mecânica e ótica geométrica. A expectativa dos autores é de que a utilização desse laboratório virtual junto aos estudantes leve a uma melhoria no nível de interpretação e argumentação dos mesmos. Ainda no que se refere aos simuladores, como defende Zacharia e Anderson (2003), um ensino de física efetivo deve ser tal que encoraje os estudantes a aprender de modo a atingir uma compreensão conceitual do fenômeno. Nesse mesmo trabalho, os autores defendem que as simulações computacionais podem ser usadas no sentido de fomentar experiências interativas com o fenômeno físico, levando os estudantes a eventuais mudanças em suas percepções acerca do conceito estudado. Por outro lado, afirmam que é necessário se ter certa cautela no desenvolvimento de simulações de fenômenos físicos para o ensino de física. Como afirma Yeo e seus colaboradores (2004), apesar de sempre se argumentar que os estudantes se sentem motivados a aprender física quando ela é ensinada no contexto do dia a dia, o desenvolvimento de programas para a simulação em tal contexto deve, sempre, garantir que os conceitos físicos permaneçam no foco do estudante.

Novak e seus colaboradores (2011) também defendem que colocar os estudantes diante de questões que tragam em si significados relacionados ao seu dia a dia faz com que eles deixem uma posição passiva e passem a aprender de um ponto de vista ativo. Esses mesmos autores argumentam sobre a maior dimensão que isso toma quando se faz uso de simuladores no ensino.

No que tange especificamente ao uso de softwares dinâmicos, objeto deste artigo, Tatar (2013), numa pesquisa realizada junto a futuros professores de matemática da Turquia, estudou o efeito da utilização desse tipo de software na percepção dos professores acerca de sua efetividade como um objeto de aprendizagem. Nesse trabalho, o autor relata que os futuros professores se mostraram mais confiantes dado o fato de que podem diretamente observar algo mais concreto, complementando a formação básica e tradicional do curso superior de formação de professores de matemática naquele país. $\mathrm{O}$ autor também aponta a alta importância em se treinar os futuros professores no uso e aplicação das TIC em sua futura atuação docente.

Mehanovic (2011) desenvolveu um estudo onde observou dois diferentes desdobramentos no uso do GeoGebra no ensino de matemática, mais precisamente, integrais. Um deles é aquele do ponto de vista dos estudantes, o outro, do ponto de vista dos professores. No que diz respeito aos estudantes, a autora indica a importância de se mostrar, de forma bastante clara e evidente, o potencial didático do GeoGebra no aprendizado do tema em questão. Além disso, afirma que é necessário muito cuidado no processo de ensinar aos estudantes sobre como utilizar o software como uma ferramenta. Nesse momento é importante que se respeite as necessidades individuais que cada um deles apresenta. No sentido de evitar a desmotivação do estudante frente ao software, aponta que o mesmo deve ser utilizado, além das aulas, no processo de avaliação, isto é, realizar provas e exames utilizando o software. Já na perspectiva dos professores, a autora relata ter observado diferentes níveis de percepção em relação ao potencial do GeoGebra para o ensino do tema em questão. Alguns professores demonstraram não perceber o potencial didático do software, 
considerando-o apenas como um elemento de visualização. Nesse sentido, ela aponta a necessidade do desenvolvimento de competências, junto aos professores, em integrar o software dinâmico às suas aulas.

Gobbi e Leivas (2014), em um artigo oriundo de um fragmento de uma dissertação de mestrado profissionalizante em ensino de matemática, utilizaram o GeoGebra como ferramental no ensino do cálculo de perímetros e áreas de figuras planas junto a estudantes do 60 ano do EF. Utilizando o protocolo da Engenharia Didática (ED) e pautados pelo fato de que o uso do GeoGebra deixou a aula mais dinâmica, os autores concluíram que a utilização desse software dinâmico no ensino dos temas acima mencionados resultou em melhorias no aprendizado apresentado pelos estudantes.

Aplicações do tipo simuladores e/ou animações se tornam mais eficientes e atrativos ao trabalho docente quando o caráter "mãos à massa" se dá de forma efetiva, isto é, quando a aplicação permite ao professor uma real interação com o mesmo. O desenvolvimento de aplicações utilizando o GeoGebra apresenta características no sentido de atender a essa demanda. Ele permite ao professor ampla interação com o código que leva à exibição da simulação do fenômeno físico. Essa forte interação é alcançada uma vez que o código fonte da aplicação fica totalmente acessível ao docente, permitindo a ele ajustá-lo de acordo com sua necessidade perante a turma em que leciona, melhorando a qualidade da transposição didática do elemento relacionado às TIC. Isso se torna ainda mais importante se olharmos a partir do ângulo sob o qual turmas diferentes em escolas, bairros ou regiões diferentes, necessitam de uma abordagem específica de um ou de outro tema.

Neste trabalho buscamos dar nossa contribuição no uso do GeoGebra no ensino de tópicos relacionados à física. Utilizando esse software dinâmico, desenvolvemos um simulador virtual para o ensino do movimento harmônico simples (MHS). Partimos da projeção ortogonal sobre o eixo dos " $x$ " da trajetória de um corpo que descreve um movimento circular uniforme (MCU). Argumentamos também sobre algumas possibilidades de abordagens e discussões que podem ser utilizadas pelo professor ao explorar junto à suas turmas o simulador que aqui apresentamos.

\section{O GeoGebra e o ensino de física}

Neste trabalho utilizamos o software dinâmico GeoGebra cujo nome vem da aglutinação das palavras geometria e álgebra. Tal software combina conceitos da geometria e da álgebra em uma interface amigável e intuitiva, permitindo ao professor uma rápida e eficaz implementação de códigos para a apresentação de temas em diversas áreas. Nele é possível trabalhar com geometria, álgebra, tabelas, gráficos, estatística e cálculo (HOHENWARTER, 2016). Dado que a física, nos diferentes níveis de ensino, se vale desses conteúdos e ferramentas da matemática é, então, natural que seus conteúdos possam ser explorados utilizando o GeoGebra.

Outra característica importante do GeoGebra é que, devido ao fato de ser escrito na linguagem Java, é possível utilizá-lo em diferentes plataformas, incluindo tablets e smartphones, além dos computadores tradicionais (HOHENWARTER, 
2016). Trata-se de um software de uso gratuito que foi desenvolvido em 2001 por Markus Hohenwarter e, desde então, vem sendo aprimorado.

Na figura 1 apresentamos um instantâneo da tela inicial do GeoGebra versão 5.0. Nela podemos ver as janelas de álgebra e de visualização. Dado que essas duas janelas trabalham lado a lado e estão, portanto, sempre visíveis ao usuário, uma dada operação realizada na janela de álgebra tem, imediatamente, sua representação algébrica mostrada na janela de visualização. Isso permite, por exemplo, que o professor proceda com a variação do valor de uma dada variável na janela de álgebra que, imediatamente, altera a representação visual da janela ao lado. Isso se caracteriza como uma excelente ferramenta para que o professor apresente a seus estudantes as relações entre as variáveis de um dado fenômeno físico.

Na parte superior da figura 1 é mostrada a barra de ferramentas que, ao clicar num dado item, habilita uma das funções como, por exemplo, a inserção de uma reta através do fornecimento de dois pontos a ela pertencentes.

Figura 1 - Tela inicial do GeoGebra versão 5.0. À esquerda é apresentada a janela de álgebra e à direita a janela de visualização. Logo acima dessas duas janelas aparece a barra de ferramentas.

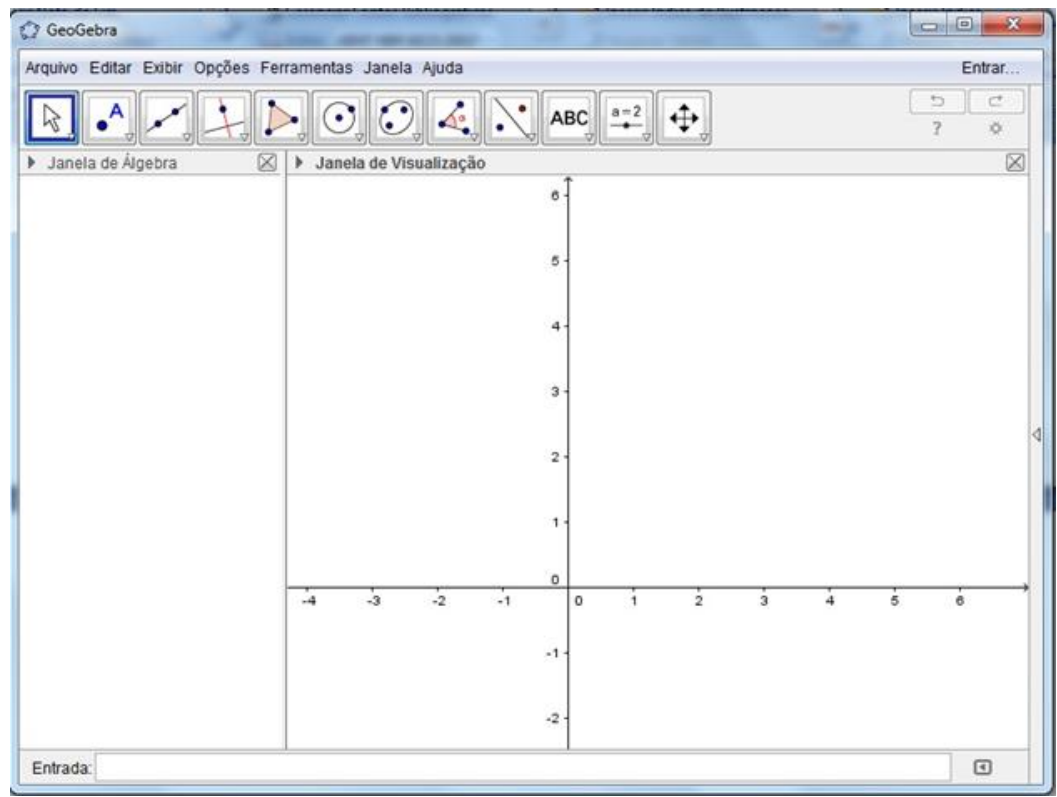

Uma característica bastante importante é que o GeoGebra permite a inserção de elementos que são algebricamente guiados por um procedimento iterativo. Essa iteratividade permite que o professor de física desenvolva aplicações de caráter dinâmico, isto é, é possível criar elementos que se movem na tela. Assim, elementos que eventualmente seriam representados de forma estática na lousa, podem ser transformados em elementos dinâmicos e o professor pode, por exemplo, pausar o movimento e aproveitar os diferentes "instantâneos" para discutir e argumentar junto a seus estudantes sobre as características do fenômeno físico em diferentes instantes de tempo.

Outro ponto importante se relaciona à "matematização" encontrada no ensino de física no EM. Os simuladores, em geral, trazem embarcada em si toda a matemática relacionada ao fenômeno de que trata, camuflando-a. Com isso, cabe 
ao docente explorá-la, na lousa por exemplo, enquanto apresenta e discute o fenômeno com o auxílio da simulação e/ou animação. Nesse sentido, outra importante vantagem do uso do Geogebra no ensino de física no EM é que ele permite ao professor explorar a matemática por trás do fenômeno físico, por mais avançada que esta seja, sem eventualmente omiti-la. As equações e relações matemáticas pertinentes ao fenômeno estão todas acessíveis ao docente que pode, durante a própria aula, realizar alterações nessas equações enquanto os estudantes acompanham graficamente o comportamento do sistema físico em estudo. Isso assegura ao professor a possibilidade de "jogar" com os valores das variáveis do problema em questão, levando os estudantes a uma melhor compreensão das relações e influência de cada uma delas no fenômeno físico em estudo.

Em relação ao ensino de física, nos últimos anos, alguns trabalhos utilizando softwares dinâmicos têm surgido. Malgieri e seus colaboradores (2014) utilizaram - GeoGebra associado às integrais de caminho para desenvolver uma sequência de simulações interativas. Nesse trabalho, tais simulações foram utilizadas como ferramenta no processo de ensino de física quântica. Os autores concluíram que tal abordagem mostrou-se de forma muito promissora, pois permitiu que os estudantes apresentassem um elevado grau de conhecimento acerca do tema em um tempo relativamente curto. Eles ainda ressaltam que, dado o fato da transparência do software em relação à apresentação das relações matemáticas utilizadas (visíveis na janela de álgebra), o uso do GeoGebra permitiu mostrar aos estudantes que por trás da simulação utilizada não há um algoritmo complexo e exótico fazendo com que a simulação aconteça. Outra observação importante é do ponto de vista dos professores. Os autores relatam que o uso do GeoGebra pode encorajá-los a modificar e melhorar os códigos utilizados, pois a interface na qual a construção dos códigos se dá é familiar aos professores da área. Em outro trabalho, Aguiar (2009) utiliza outro software de geometria dinâmica, o tabulae , para discutir como ele pode ser transformado em um ambiente virtual de aprendizagem de ótica geométrica. Ele conclui que a utilização de softwares dessa natureza, no ensino desse tema, dá aos estudantes uma perspectiva mais intuitiva e menos sujeita a erros de interpretação. A força dos softwares dinâmicos, indicada pelos trabalhos acima relacionados, é uma consequência do fato desses softwares permitirem combinar álgebra computacional e geometria dinâmica.

Em relação à cinemática no EM, Marciuc e colaboradores (2016) desenvolveram um modelo interativo utilizando o GeoGebra para o estudo do movimento de projéteis. Nessa aplicação foi apresentada, de forma dinâmica na tela do computador, a evolução da posição do projétil em função do tempo bem como a evolução de sua velocidade, também em função do tempo. Nos dois casos o professor tinha como opção alterar o ângulo de lançamento e/ou a velocidade inicial do lançamento. Isso permitiu aos estudantes visualizar em tempo real a implicação de cada uma dessas variáveis no movimento do projétil. Além disso, dada a facilidade de manipulação do modelo físico que rege o que é apresentado na tela, os autores também exploraram junto aos estudantes uma situação mais próxima do real, afastando-se da constante "...numa situação ideal,...". Nessa situação real foi considerada uma força horizontal, sempre desprezada nas abordagens tradicionais desse tema. Essa força pode, por exemplo, ser a resistência imposta pelo ar ao movimento horizontal do projétil. Com isso o professor consegue mostrar aos estudantes o comportamento de um fenômeno da forma que o mesmo se dá na natureza, sem apelar para aproximações, por 
exemplo. Souza e colaboradores (2010) desenvolveram um trabalho onde aplicaram o GeoGebra para o estudo de fenômenos oscilatórios, mais precisamente o movimento pendular. Nesse trabalho, numa perspectiva metacognitiva, eles fazem uma indicação de como utilizar o software dinâmico na análise desse fenômeno físico. Concluíram que o uso desse software permitiu mostrar aos estudantes a importância das diferentes variáveis e parâmetros envolvidos no fenômeno.

\section{Fundamentação teórica}

Os movimentos periódicos sempre estiveram presentes no dia a dia da humanidade. Desde tempos muito remotos o homem se apoia na regularidade do movimento ou propriedades periódicas de certos elementos da natureza para organizar sua vida. Por exemplo, a agricultura em tempos antigos se apoiava no movimento periódico da Lua para determinar o momento ideal para o plantio de um dado alimento. A periodicidade de eventos naturais também permitiu ao homem iniciar o estudo da cronologia, criando e desenvolvendo sistemas de medição do tempo. Medir o tempo é um excelente exemplo da implicação da boa compreensão dos movimentos periódicos na vida das pessoas. 0 padrão adotado era, no início, o período de rotação do planeta Terra em torno de seu próprio eixo, agora são as transições eletrônicas que se dão no interior de um átomo de césio133. Este último método, o relógio atômico, permite medir o tempo com uma precisão de um bilionésimo de segundo por dia. Equivalentemente, para esse relógio cometer um erro de 1 segundo é necessário que se passe algo da ordem de 3 mil anos.

Essa excelente precisão que se atingiu na medida do tempo é fundamental para o bom funcionamento de elementos que alguns de nós, principalmente os mais jovens, não concebem a vida sem eles. Dentre tais elementos estão o GPS, a internet, os sistemas de telecomunicações, os computadores, os smartphones etc. Assim, o conhecimento de fenômenos oscilatórios, tais como o MHS, se constitui como um elemento crucial na formação de um cidadão ativo em sua comunidade, pois auxilia no alcançar do objetivo que é compreender e ter consciência das implicações que a ciência tem em sua vida.

Nossas experiências como docentes no EM e no ensino superior (ES) têm nos colocado face a face com as dificuldades e complicações inerentes ao ato de se ensinar o MHS. O elevado grau de "matematização" necessário à compreensão e conhecimento do tema, associado ao pouco dinamismo que aulas expositivas utilizando apenas a lousa propiciam caracterizam-se, nos dias atuais, como complicadores no processo ensino-aprendizagem do tema. Já existem à disposição, e muitas delas gratuitamente, animações e simulações que têm como objetivo apoiar o trabalho do professor nesse processo. Porém, tais aplicações dão conta apenas de melhorar o dinamismo da aula, diminuindo o esforço e ocupação do professor em fazer as representações gráficas na lousa. Essas representações gráficas na lousa, além do tempo que tomam, não conferem aos estudantes uma oportunidade de visualização realmente dinâmica do movimento, item indispensável à boa compreensão e aprendizado do tema.

A figura 2 mostra uma representação esquemática, no plano cartesiano, de um corpo que descreve um MCU. Nessa figura, $\phi(t)$ representa a posição angular 
instantânea da partícula (foguete), $v$ $\rightarrow$ é seu vetor velocidade instantânea (ou velocidade tangencial), $v{ }$ X é a projeção ortogonal dessa velocidade sobre o eixo " $x$ ", $a$ _ cp é o vetor aceleração centrípeta e A é o raio da trajetória.

Figura 2 - Representação esquemática de um corpo descrevendo um movimento circular uniforme. São representados o vetor velocidade instantânea, sua projeção ortogonal ao longo do eixo "x" e o vetor aceleração centrípeta.

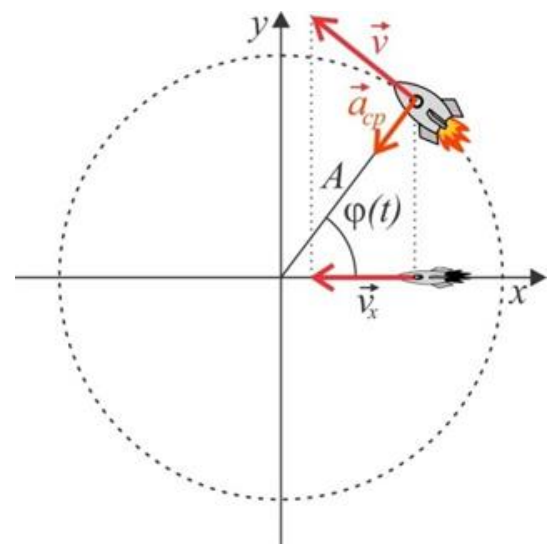

Quando tratamos do MHS associado à projeção ortogonal de um MCU sobre o eixo " $x$ ", como representado na figura 2 , a posição dessa projeção em função do tempo é dada por:

$$
\begin{gathered}
x(t)= \\
A \cos [\varphi(t)] .
\end{gathered}
$$

Dado que o corpo descreve um MCU, sua posição angular é uma função do tempo e é dada por:

$$
\begin{array}{r}
\varphi(t)= \\
\varphi_{0}+\omega t,
\end{array}
$$

onde $\varphi_{0}$ é a posição angular inicial da partícula, isto é, $\varphi_{0}=\varphi(t=0)$ e $\omega$ é sua velocidade angular (ou frequência angular), ou seja, mede a taxa na qual a posição angular está variando.

Associando as equações (1) e (2) obtemos a equação horária das posições da partícula (na verdade da projeção ortogonal da partícula) que descreve o MHS, isto é,

$$
\begin{aligned}
& x(t)= \\
& \operatorname{Acos}\left(\varphi_{0}+\right. \\
& \omega t) .
\end{aligned}
$$


A equação (3) descreve o comportamento temporal da posição da projeção ortogonal sobre o eixo dos " $x$ " do corpo que gira descrevendo um MCU. Ainda na equação (3), $A$ é a amplitude do movimento que coincide com o raio do MCU.

Do ponto de vista da apresentação do fenômeno seguido da introdução das equações (1), (2) e (3), cabe ao professor apresentar os argumentos e justificativas, sempre mantendo a física do fenômeno no centro de seu discurso. Porém, no que se relaciona à visualização do fenômeno e na efetiva compreensão das relações entre as variáveis, o uso de um elemento computacional dinâmico, como o que apresentamos neste trabalho, apresenta um bom potencial de aplicação.

Outro ponto crítico no estudo do MHS é a velocidade da partícula. Devido ao fato de no MHS a aceleração não ser constante ${ }^{1}$, sua velocidade, ou seja, a velocidade com a qual a projeção do corpo se move ao longo do eixo " $x$ " não é uniforme e nem uniformemente variada. Isso apresenta grande distanciamento em relação aos temas abordados em momentos anteriores no estudo do movimento retilíneo e uniforme (MRU) e do movimento retilíneo uniformemente variado (MRUV). Tal propriedade do MHS é um elemento que apresenta um nível de complicação mais elevado no momento de sua apresentação. Porém, novamente, o uso de uma simulação virtual que permita ao professor manipular os parâmetros e/ou variáveis do modelo matemático que descreve o fenômeno físico se mostra útil, pois é possível pausar o movimento do corpo que descreve o MCU e obter as características vetoriais da velocidade e da aceleração naquele instante. Isso assegura ao professor a possibilidade de mostrar ao estudante, matemática e visualmente, como essas grandezas se comportam nesse tipo de movimento.

Essa característica da aceleração não constante faz parte da natureza do MHS. Isso somado ao fato de que tal aceleração possui sempre sentido oposto àquele do vetor deslocamento, se caracteriza como uma assinatura do MHS.

A velocidade no MHS pode ser obtida através da taxa de variação de sua posição em relação ao tempo, isto é:

$$
\begin{aligned}
& \quad v(t)= \\
& \frac{d x(t)}{d t}= \\
& -\omega A \operatorname{sen}\left(\varphi_{0}+\right. \\
& \omega t) .
\end{aligned}
$$

Como já mencionado e como indica a equação (4), a velocidade no MHS não obedece aos conceitos do MRU e MRUV, ou seja, ela não é constante e nem varia de forma uniforme, na verdade ela obedece a uma função seno.

Já a aceleração, que é a taxa temporal na qual a velocidade varia, é dada por:

Página | $33{ }^{1}$ Isso se deve ao fato de, no MHS, a força depender da posição da partícula. Como a força é uma grandeza dinâmica e, aqui, nos atermos apenas à cinemática do movimento, não daremos maior profundidade ao tema. 
O sinal negativo na equação (5) indica que a orientação do vetor aceleração se opõe àquela do vetor deslocamento.

Além do fato de haver uma aceleração que não é constante, ao envolver funções do tipo seno e cosseno, eleva-se o nível de "matematização" até então enfrentado pelos estudantes em outros momentos da disciplina de física. Por outro lado, não se pode permitir que tal parte do conteúdo, isto é, seu modelo matemático, seja omitido, pois imporia uma lacuna na formação do estudante em relação a essa importante característica da natureza.

Em nossa proposta, trazemos embarcada - mas não escondida - em nosso simulador toda essa matemática, exceto a parte diferencial, de modo que o professor pode apresentá-la aos estudantes de uma forma mais objetiva e dinâmica. Ele ainda tem a opção de, com um simples clique do mouse, alterar os valores das variáveis em questão, mostrando aos estudantes a mudança na dinâmica do movimento. Na verdade, o professor fica com a possibilidade de explorar com mais detalhes o modelo matemático detrás do MHS dado o dinamismo que a animação associada ao simulador dá a sua aula.

\section{Metodologia}

Pautamo-nos aqui pelas condições de que a qualidade e o cunho pedagógico relacionado a um dado software, como o que utilizamos, não estão no próprio programa, mas sim em quem o aplica em situações de ensino (SOUZA et al., 2010). Desta forma, a experiência docente em sala de aula, ministrando os diferentes temas relacionados à física, junto a uma boa formação (seja ela regular ou continuada), é que asseguram uma real efetividade do elemento das TIC no auxílio ao ensino de física.

Assim, buscamos desenvolver o simulador observando dois elementos fundamentais no processo ensino do MHS no EM. Primeiramente, respeitamos a apresentação e utilização da matemática relacionada ao tema do MHS. Nesse contexto, deixamos explícitas e sempre acessíveis ao usuário do simulador as equações que regem o MHS (equações (3), (4) e (5)). Dessa forma o professor, por opção ou intervenção do estudante, pode facilmente remeter-se a elas e, eventualmente, proceder com a alteração no valor de alguma variável ou de algum parâmetro. Ainda no contexto dos parâmetros e variáveis do problema, optamos por apresentar alguns valores pré-determinados e acessíveis via ícone na tela de visualização do GeoGebra de forma que o professor possa, fácil e rapidamente, alterar entre alguns valores que levam a comportamentos bastante distintos da simulação. Em segundo lugar, com o intuito de não criar elementos que levem à distração e que possam tirar o estudante do foco que é o fenômeno físico, criamos uma animação num espaço limpo, sem exageros relacionados às imagens e planos de fundo. Em outros termos, embora o tema que abordamos não seja simples, optamos por uma animação simples, porém eficaz. 
Além disso, construímos o simulador de tal forma que a sequência de abordagem do conteúdo possa ser direta e naturalmente respeitada pelo professor. Em outros termos, o simulador foi desenvolvido para que sua utilização pelo docente ocorra de forma intuitiva. Basta que o professor desenvolva sua aula como faria usando exclusivamente a lousa, apenas substituindo o processo de representação dos elementos na lousa por "cliques" no simulador.

\section{Discussão dos resultados}

Nesta seção apresentamos e discutimos a forma final de nossa proposta de um simulador virtual para o desenvolvimento dos estudos relacionados ao $\mathrm{MHS}$ junto aos estudantes do EM. Iniciamos fazendo uma apresentação geral do simulador e apontando suas funcionalidades. Em seguida, passamos para a apresentação e discussão das possibilidades de utilização do mesmo no processo de ensino do tema.

A figura 3 apresenta uma visão geral da tela inicial do simulador para o MHS tal e como ele se apresenta no momento em que o usuário o executa pela primeira vez. Nela é possível observar a janela de visualização com a parte "visual" da simulação sendo apresentada no centro dessa janela, a janela de álgebra onde estão disponíveis ao usuário todos os elementos relacionados à construção do simulador e, na parte superior da figura, as ferramentas do próprio GeoGebra.

Figura 3 - Tela inicial do Simulador para o Movimento Harmônico Simples. Na janela de álgebra são apresentados os elementos utilizados na construção do simulador e na janela de visualização os comandos básicos e as caixas para seleção dos elementos que se deseja mostrar na tela.

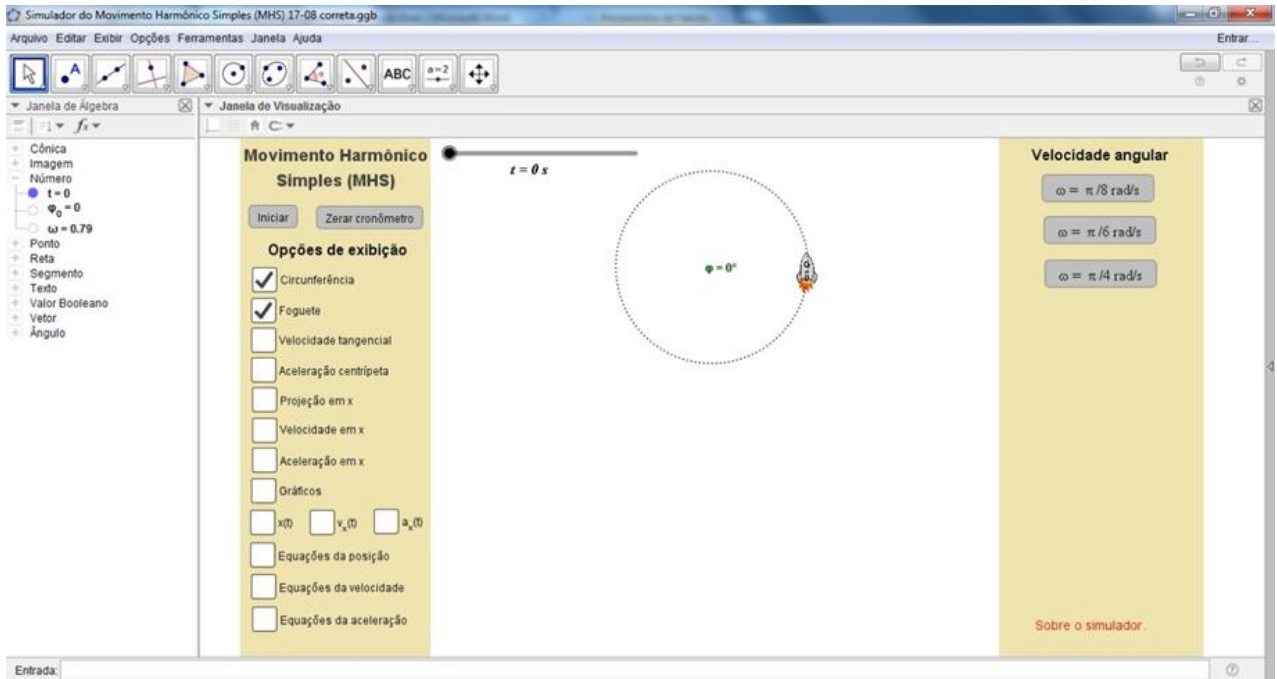

Na figura 4 é apresentada apenas a janela de visualização do GeoGebra. Nessa figura, à sua esquerda e acima, aparecem os botões "Iniciar" e "Zerar cronômetro" que permitem ao usuário, respectivamente, iniciar a simulação e fazer com que a variável "tempo" do simulador volte a receber o valor "zero", ou seja, clicar em tal botão equivale a zerar o cronômetro numa situação real. Ainda na porção 
esquerda dessa figura, é mostrada uma aba com as "Opções de exibição". Nessa aba o usuário pode escolher aquilo que ele deseja que seja mostrado na tela e aquilo que deve ser ocultado, só vindo a ser apresentado no momento em que ele mesmo julgar oportuno.

Na parte direita da figura 4, na aba "Velocidade angular", o usuário pode escolher entre três diferentes valores previamente definidos $(\pi / 8 \mathrm{rad} / \mathrm{s}$, $\pi / 6 \mathrm{rad} / \mathrm{s}$ e $\pi / 4 \mathrm{rad} / \mathrm{s}$ ) e na porção inferior aparecem, também a critério do usuário, as equações da posição, da velocidade e da aceleração para o MHS.

Figura 4 - Tela do Simulador para o Movimento Harmônico Simples mostrando apenas a janela de visualização com $t=7,49 \mathrm{~s}, \phi \_0=0$ e $\omega=\pi / 4 \mathrm{rad} / \mathrm{s}$. São apresentadas todas as funcionalidades bem como as equações relacionadas ao MHS.

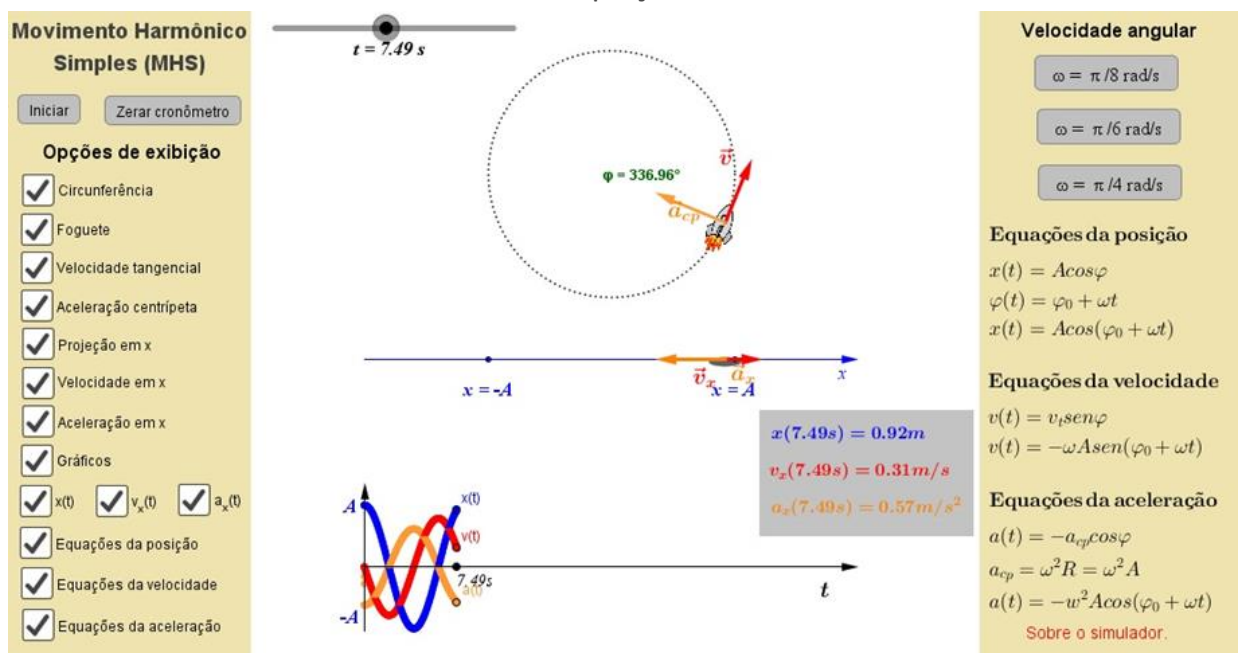

Na parte central da figura 4 é apresentada a simulação propriamente dita, isto é, sua parte visual e gráfica. No topo da parte central é mostrada a barra de tempo (controle deslizante). Ainda na parte superior aparece a representação de um foguete que descreve um MCU. Tal movimento será utilizado para se chegar às propriedades do MHS que é o movimento descrito pela projeção ortogonal do movimento do foguete. Junto com o foguete são representados seus vetores velocidade tangencial $(\vec{v})$ e aceleração centrípeta $\left(\vec{a}_{c p}\right)$. No centro da trajetória circular aparece o valor da posição angular instantânea do foguete $(\varphi(t))$. Logo abaixo aparece a representação do eixo " $x$ " sobre o qual aparece a projeção ortogonal (sombra do foguete representada pela elipse em cinza) do MCU descrito pelo foguete. Como é possível observar, sobre esse eixo aparecem os limites ( $x=$ $-A$ e $x=A$ ) do MHS, ou seja, sua amplitude. Tal amplitude, no simulador, foi definida como $A=1 \mathrm{~m}$. Ainda sobre esse eixo e acompanhando solidariamente o movimento da projeção do foguete aparecem as projeções dos vetores velocidade tangencial $\vec{v}$ e aceleração centrípeta $\vec{a}_{c p}$ que são, na verdade, os vetores velocidade $\left(\vec{v}_{x}\right)$ e aceleração $\left(\vec{a}_{x}\right)$ do MHS. As equações para essas variáveis, bem como para $x(t)$, podem ser visualizadas na aba direita do simulador. Mais abaixo aparece a representação gráfica do MHS, bem como os valores instantâneos de $x(t), v_{x}(t)$ e $a_{x}(t)$ (caixa sombreada em cinza à direita do gráfico). Os gráficos, como pode ser observado na aba à esquerda (Opções de exibição), podem ser apresentados separadamente ou todos juntos de forma sobreposta. 
Do ponto de vista da utilização e aplicação do simulador em sala de aula junto aos estudantes do EM, o professor tem à sua disposição uma ferramenta coadjuvante no processo ensino-aprendizagem do MHS. Como, na porção central, é possível observar os vetores velocidade tangencial $(\vec{v})$ e aceleração centrípeta $\left(\vec{a}_{c p}\right)$ do foguete que descreve a trajetória circular, o professor pode mostrar aos estudantes que os módulos dessas grandezas permanecem constantes e que suas direções e sentidos é que se alteram à medida que o tempo passa. Apoiando-se agora na representação mostrada no eixo dos " $x$ " que aparece logo abaixo da representação da trajetória circular, o professor tem à sua disposição um elemento dinâmico que permite ilustrar de forma precisa aos estudantes o comportamento dos vetores velocidade $\left(\vec{v}_{x}\right)$ e aceleração $\left(\vec{a}_{x}\right)$ à medida que o tempo passa.

Outro elemento com potencial de eficácia no auxílio a melhor compreensão do MHS por parte dos estudantes está na barra de tempo. O professor, ao clicar uma única vez sobre o comando deslizante da variável tempo, tem a opção de avançar ou retroceder no tempo com as teclas direcionais do teclado. Isso permite mostrar aos estudantes como se dá a evolução temporal de $x(t), \vec{v}_{x}(t)$ e $\vec{a}_{x}(t)$ e seus respectivos módulos. No caso ilustrado na figura 4 , ao se pressionar a tecla direcional para a direita o tempo evolui de $\Delta t=0,01 \mathrm{~s}$ a partir de $t=7,49 \mathrm{~s}$ e os estudantes podem observar, no centro da janela de visualização, $\vec{v}_{x}(t)$ diminuindo seu módulo (diminuindo de tamanho) até desaparecer por completo e $\vec{a}_{x}(t)$ tendo seu módulo aumentado até atingir seu valor máximo, que no caso ilustrado é $a_{x}(t=8 \mathrm{~s})=0,62 \mathrm{~m} / \mathrm{s}^{2}$. Este último valor pode ser observado na caixa sombreada em cinza à direita do gráfico.

O professor pode, nesse momento, evidenciar aos estudantes que eles estão diante de um exemplo de movimento que não tem aceleração constante. 0 professor pode, ainda, trazer à baila outros tipos de movimento que também apresentem essa característica, mesmo que de um ponto de vista apenas fenomenológico.

O gráfico mostrado na parte inferior apresenta, separadamente ou simultaneamente e de forma sobreposta, a evolução temporal das variáveis $x(t)$, $v_{x}(t)$ e $a_{x}(t)$. Em um primeiro momento o professor pode apresentar ao estudante cada um dos três gráficos separadamente, evidenciando e discutindo o comportamento de cada uma das variáveis envolvidas no fenômeno físico. Feito isso, o professor pode explorar com os estudantes todos os diferentes regimes de movimento que ocorrem no MHS. Dado que a aceleração no MHS não é constante, os regimes possíveis são: "progressivo e acelerado", "progressivo e retardado", "retrógrado e acelerado" e "retrógrado e retardado". Avaliando junto com os estudantes as diferentes configurações dos gráficos de $v_{x}(t)$ e $a_{x}(t)$ em diferentes instantes de tempo é possível se observar os intervalos de tempo nos quais esses quatro diferentes regimes ocorrem. Por exemplo, no instante de tempo ilustrado na figura 4 , o regime é o "progressivo e retardado" dado que o vetor $\vec{v}_{x}(t)$ aponta no sentido positivo do eixo " $x$ " e $\vec{a}_{x}(t)$ no sentido oposto.

De um ponto de vista um pouco mais matemático e aproveitando as equações que podem ser exibidas à direita da janela de visualização, o professor pode utilizar o gráfico para mostrar aos estudantes que os máximos e mínimos das variáveis $x(t)$ e $a_{x}(t)$, mesmo sendo estas duas variáveis regidas temporalmente por uma função cosseno, ocorrem sempre em oposição de fase, isto é, quando $x(t)$ é máximo $a_{x}(t)$ é mínimo e vice-versa. Com o auxílio das equações do MHS, ele pode mostrar aos estudantes que isso ocorre devido ao sinal negativo na equação 
para a aceleração. Nesse momento, embora a discussão esteja no contexto da cinemática do MHS, o professor já pode chamar a atenção dos estudantes para o sistema massa-mola e o caráter restaurador da força no MHS. O mesmo não ocorre com $v_{x}(t)$ dado que sua dinâmica temporal é regida por uma função seno. Embora o simulador permita ao professor mostrar na tela as equações do MHS, é recomendável que ele as deduza na lousa, demonstrando-as.

Na janela de álgebra, como ilustrado na figura 5, é possível observar que apenas a classe de variáveis "número" aparece visível ao professor e aos estudantes. As demais classes têm suas variáveis não mostradas na tela. O objetivo dessa condição inicial para a janela de álgebra é torná-la não poluída, facilitando o acesso do usuário às três principais variáveis do MCU, e consequentemente do MHS, que são $t, \varphi_{0}$ e $\omega$.

Figura 5 - Instantâneo da janela de álgebra do simulador para o Movimento Harmônico Simples com $\mathrm{t}=7,49 \mathrm{~s}, \phi \_0=0$ e $\omega=\pi / 4 \mathrm{rad} / \mathrm{s}$.

\begin{tabular}{|c|c|}
\hline \multicolumn{2}{|c|}{$\equiv \mid \equiv \downarrow \nabla f x \vee$} \\
\hline \multicolumn{2}{|c|}{ + Cônica } \\
\hline \multirow{3}{*}{\multicolumn{2}{|c|}{$\begin{array}{l}+\quad \text { Imagem } \\
\text { Número } \\
\mathbf{t}=7.49\end{array}$}} \\
\hline & \\
\hline \multirow{2}{*}{\multicolumn{2}{|c|}{$\begin{array}{l}\mathbf{t}=\mathbf{7 . 4 9} \\
\varphi_{0}=0\end{array}$}} \\
\hline & \\
\hline \multicolumn{2}{|c|}{$\omega=\mathbf{0 . 7 9}$} \\
\hline \\
\hline \multicolumn{2}{|c|}{ + Reta } \\
\hline+ & Segmento \\
\hline \multicolumn{2}{|c|}{ Texto } \\
\hline+ & Valor Booleano \\
\hline \multicolumn{2}{|c|}{ Vetor } \\
\hline \multicolumn{2}{|c|}{ + Ângulo } \\
\hline
\end{tabular}

É possível observar nessa na figura que $t=7,49 \mathrm{~s}, \varphi_{0}=0$ e $\omega=0,79 \mathrm{rad} / \mathrm{s}$ $(\pi / 4 \mathrm{rad} / \mathrm{s}$ aproximado para duas casas decimais). Em relação à posição angular inicial e à velocidade angular, a vantagem de tê-las abertas e acessíveis ao usuário é o fato de que o professor pode atribuir a elas os valores que lhe for conveniente ou necessário no contexto da sala de aula. Para isso basta que o usuário clique duas vezes sobre o número atribuído à variável que deseja alterar. Feito isso, basta digitar o novo valor. Apesar dessa funcionalidade, como já apresentado anteriormente, o simulador já traz na janela de visualização 3 valores préconfigurados para a velocidade angular.

Em relação às demais variáveis, que não aparecem explicitamente na janela de álgebra mostrada na figura 5, estas também podem ser manipuladas pelo usuário bastando clicar sobre o símbolo "+" que aparece à esquerda do nome da classe de variáveis. Essa funcionalidade do simulador, permitida pelo GeoGebra, garante ao professor a possibilidade de mostrar aos estudantes que os movimentos, gráficos e valores que aparecem na janela de visualização não surgem devido a um mero passe de "mágica". O professor tem diante de si a possibilidade de mostrar aos estudantes que o que rege cada movimento, gráfico 
alteração e/ou melhoria na apresentação do simulador, basta modificar o código de acordo com sua necessidade e, dado que a linguagem é familiar a professores dessa área do conhecimento, sem maiores dificuldades.

\section{Conclusões}

Neste trabalho apresentamos nossa proposta de simulador virtual desenvolvido utilizando o software dinâmico GeoGebra. Essa simulação tem por objetivo colaborar com o trabalho docente no processo ensino-aprendizagem de temas relacionados ao MHS.

O simulador aqui apresentado, dada a sua estrutura de construção que parte das três variáveis indispensáveis ao estudo do $\operatorname{MHS}\left(t, \varphi_{0}\right.$ e $\left.\omega\right)$ e o respeito em relação às equações matemáticas que modelam o fenômeno físico, asseguram ao usuário qualidade e verossimilhança. No que tange especificamente à estrutura visual do simulador, as abas de operação colocadas lateralmente com a parte visual mantida no centro, e sem elementos gráficos que possam induzir o estudante a se distrair, mantém o fenômeno e sua descrição física no centro das atenções. Em outros termos, o simulador tem uma apresentação limpa com aspecto visual leve, não deixando que a física deixe de ser o foco das atenções dos estudantes.

A ordem na qual as "Opções de exibição" aparecem é tal que respeita uma ordem desejada no processo de ensino do tema, permitindo que o professor possa ir acrescentando elementos à tela de acordo com o evoluir de sua argumentação e compreensão do tema por parte dos estudantes. Esse caráter intuitivo assegura uma fácil e rápida adaptação do professor em relação a seu uso em sala de aula.

Em relação à construção do simulador, concluímos que a utilização do GeoGebra como plataforma para o desenvolvimento é bastante acessível e de utilização relativamente simples. Isso indica que o professor pode, com certa facilidade e agilidade, criar simuladores e animações que contribuam com a qualidade de suas aulas e do aprendizado de seus estudantes. A dinâmica das imagens, que suplantam em muito aquela dos desenhos feitos na lousa, trazem um caráter mais moderno à aula, podendo levar a um ensino com mais significação.

Ainda em relação ao GeoGebra, o fato de o código utilizado no desenvolvimento do simulador ficar sempre acessível ao usuário, dá uma caráter mais flexível quando comparado a outros simuladores que, apesar da boa qualidade que apresentam, trazem toda sua programação não acessível ao usuário. $O$ acesso ao código permite que o professor, quando solicitado, apresente a seus estudantes o que "tem detrás" do simulador, permitindo que estes últimos observem a relação direta do código com o modelo matemático do fenômeno físico em estudo.

Por fim, e concordando com Mehanovic (2011), embora nosso simulador apresente características que podem levar a uma melhor atuação do professor e aprendizado mais significativo por parte dos estudantes em relação ao tema aqui abordado, recomendamos que nos momentos de avaliação ele também seja utilizado. 


\title{
A virtual simulator to teach the Simple Harmonic Oscillator developed using the GeoGebra
}

\begin{abstract}
In this work we present a virtual simulator to teaching about the Simple Harmonic Oscillation. We developed the simulator using the dynamic software GeoGebra. The simulator shows a graphical interface that is quite clear end objective, allowing the teacher to explore the phenomenon in an intuitive way along with the students in secondary schools. The fact that the code behind the simulator is accessible allows the user to proceed with adjustments. The simulator shows potential in improving the teaching-learning process and it can bring the students to a more meaningful learning experience.
\end{abstract}

KEYWORDS: Teaching physics. Information and communication technologies applied to teaching. Virtual simulator. GeoGebra. 


\section{REFERÊNCIAS}

AGUIAR, C. E. Óptica e geometria dinâmica. Revista Brasileira de Ensino de Física, São Paulo, v. 31, n. 3, p. 3302/1 - 3302/5, julho 2009.

BRIGGLE, J. Analysis of pendulum period with an iPod touch/iPhone. Physics Education, v. 48, n. 3, p. 285-288, maio 2013.

ESCOBAR, J. H. et al. Virtual experimentation in electromagnetism, mechanics and optics: web-based learning. Journal of Physics: Conference Series, v. 687, p. 012078/1-012078/4, fevereiro 2016.

HOHENWARTER, M. GeoGebra. GeoGebra, 2016. Disponivel em: <https://www.geogebra.org>. Acesso em: 14 abril 2016.

LEIVAS, J. C. P.; GOBBI, J. A. O software GeoGebra e a Engenharia Didática no estudo de áreas e perímetros de figuras planas. Revista Brasileira de Ensino de Ciência e Tecnologia, Curitiba, v. 7, n. 1, p. 182-199, janeiro 2014.

MALGIERI, M.; ONORATO, P.; DE AMBROSIS, A. Teaching quantum physics by the sum over paths approach and GeoGebra simulations. European Journal of Physics, v. 35, p. 1-21, agosto 2014.

MARCIUC, D.; MIRON, C.; BARNA, E. S. Using GeoGebra software in the teaching of oscillatory motions. Romanian Reports in Physics, v. 68, n. 3, p. 1-16, 2016. In press.

MEHANOVIC, S. The Potential and Challenges of the Use of Dynamic Software in Upper Secondary Mathematics. Linköping University. Linköping, p. 128. 2011. Tese de Doutorado.

MORAN, J. M. Ensino e aprendizagem inovadores com tecnologias audiovisuais. Campinas: Papirus, 2002.

NOVAK, D.; FAHLBERG-STOJANOVASKA, L.; RENZO, A. Buildung Simulators with geogebra. In: BU, L.; SCHOEN, R. Model-Centered Learning: Pathways to Mathematical Understanding Using GeoGebra. Carbondale: Sense Publishers, v. 6, 2011. Cap. 5, p. 73-89. 
SOUZA, A. R. et al. Uso de GeoGebra para analisar o movimento harmônico simples por meio do pêndulo simples. In: PIROLLA (ORG.), N. A. Ensino de ciências e matemática, IV: temas de investigação. [S.I.]: UNESP, 2010. Cap. 9, p. $175-204$

TATAR, E. The Australian Journal of Teacher Education, The Effect of Dynamic Software on Prospective Mathematics Teachers' Perceptions Regarding Information and Communication Technology, v. 38, n. 12, p. 1-16, dezembro 2013.

TIRONI, C. R. et al. A Aprendizagem Significativa no Ensino de Física Moderna e Contemporânea. Atas do IX Encontro Nacional de Pesquisa em Educação em Ciências - IX ENPEC. Águas de Lindóia: SBF. 2013. p. Brasil.

VIEYRA, R. E.; VIEYRA, C. Analyzing Forces on Amusement Park Rides with Mobile Devices. The Physics Teacher, v. 52, p. 149-151, março 2014.

YEO, S. et al. What do students really learn from interactive multimedia? A physics case study. American Journal of Physics, v. 72, n. 10, p. 1351-1358, outubro 2004.

ZACHARIA, Z.; ANDERSON, O. R. The effects of an interactive computer-based simulation prior to performing a laboratory inquiry-based experiment on students' conceptual understanding of physics. American Journal of Physics, v. 71, n. 6, p. 618-629, junho 2003.

Como citar: SOARES, A. A.; CARMO, R. Um simulador virtual para o ensino do Movimento Harmônico Simples desenvolvido utilizando o GeoGebra. Revista Brasileira de Ensino de Ciência e Tecnologia, v. 9, n. 3, 2016. Disponível em: <https://periodicos.utfpr.edu.br/rbect/article/view/4526>. Acesso em: xxx. Correspondência:

Direito autoral: Este artigo está licenciado sob os termos da Licença Creative Commons-Atribuição 4.0 Internacional.

\section{(c) (1)}

